\title{
The 'Joy-of-Use'-Button: Recording Pleasant Moments While Using a PC
}

\author{
Robert Schleicher ${ }^{1}$ and Sandra Trösterer ${ }^{2}$ \\ ${ }^{1}$ Deutsche Telekom Laboratories \\ ${ }^{2}$ Chair of Human-Machine Systems, TU Berlin, \\ Straße des 17. Juni 135, 10623 Berlin, Germany \\ robert.schleicher@tu-berlin.de, sandra.troesterer@mm.tu-berlin.de
}

\begin{abstract}
This paper describes the conceptualization and implementation of a free software tool to record positive moments while using a PC. The application runs in the background and is only visible as an icon in the system tray. Once called, the user is prompted to quantify the Joy-of-Use experience with a fivepoint rating which is saved together with a screenshot of the currently active window. The user can also mark areas in the screenshot that were relevant to the positive experience. In the advanced mode, the event can additionally be characterized by selecting typical aspects of such moments that were determined empirically, or by giving an own description in a free text field. A running version for Microsoft Windows XP and its source code are available online for other researchers and practitioners who wish to collect their own data on Joy-of-Use.
\end{abstract}

Keywords: emotion, fun, usability evaluation tool, Microsoft Windows XP.

\section{Introduction}

Current approaches in Human-Computer-Interaction claim that research should comprise more than just assessing the effective and efficient solution of the task at hand, insisting on an holistic view on the overall user experience beyond the predominant ergonomic criteria of classical usability research [1]. To describe what else makes using an application or electronic device enjoyable, different terms like emotional design [2] or hedonic quality [3] have been coined. Here, phrases like joy of use [4] illustrate that attention is paid to factors that actively promote pleasant interaction instead of simply singling out potential annoyances - similar to a development in emotion research to also examine the nature of positive emotions after predominantly enquiring into the origins of affects like fear or anger/aggression [5]. However, in both areas it sometimes appears almost more difficult to induce and capture positive moments than unpleasant ones, especially if one tries to move away from pure laboratory settings. Two interdisciplinary student projects at the Technical University of Berlin tried to investigate this issue and come up with a tool to record joy-of-use experiences. Their results are reported here. 


\section{How to Measure Joy-of-Use?}

The main purpose of the initial project was two-fold: first to obtain a broad collection of moments of pleasant human-computer-interaction and next to develop own ideas on how to measure these events in practice. To fulfill the first goal, all 12 participants (7 male, 5 female students of human factors or technical graduate studies like engineering, computer science etc. with an age range from 20 to 30 years) were asked to keep a diary for one month on when and where they enjoyed using a computer or an electronic device. The description did not have to be extensive, however, it should be clear what caused the pleasant feeling specifically and why. As well 'pleasant moments' should include all events from persistent enthusiasm to brief satisfaction anything that was somehow consciously perceived as positive.

Altogether 157 events were collected and classified with respect to typical aspects and situations in which they occurred. Surprisingly, the most frequent category was labeled time saving with events like 'using a shortcut instead of having to click through the menu tree', which is more or less equivalent to the classic usability criterion of efficiency. Other categories were for example infotainment (e.g. the 'hybrid view'-option in google maps) or availability/multifunctionality (e.g. dual use of mp3 player as external data storage). The complete list of common properties can be seen in figure 1.

Next, the most popular measurement instrument and tools to assess user satisfaction or hedonic quality of a software were determined by reviewing available literature. Besides verbal questionnaires like the SUMI (Software Usability Measurement Inventory [6]) and AttrakDiff [7], a pictogram-based rating scale, the SelfAssessment-Manikin (SAM, [8]) appeared to be the most commonly used methods. However, all instruments are usually filled in after a long interaction phase and it was in dispute to what extent they would have been able to capture the brief moments of enjoyment that were reported in the self-observations. For these transient and less intense events an unobtrusive and quick rating option seemed best-suited. Thus some kind of button that could be pressed when desired was suggested. Additional requirements were that any tool should not demand too much of the user's resources (i.e. disrupt ongoing activity) and have a clear emphasis on positive aspects of humancomputer-interaction to prevent it from being turned into an electronic complaint form.

\section{The 'Joy-of-Use'-Button}

The concept of a continuously available, but unobtrusive button was realized as a program that runs in the background and is visible only in the system tray (see Figure 1). For practical considerations it was decided to implement this application in $\mathrm{C \#}$ and choose Microsoft Windows XP as the target operating system. A stable running version and its source code is available online ${ }^{1}$.

If the user wishes to record a Joy-of-Use (JoU) experience, she calls the application with a mouse click on the icon or a self-defined keyboard shortcut and the rating

${ }^{1}$ http://www.tu-berlin.de/index.php?id=53724 


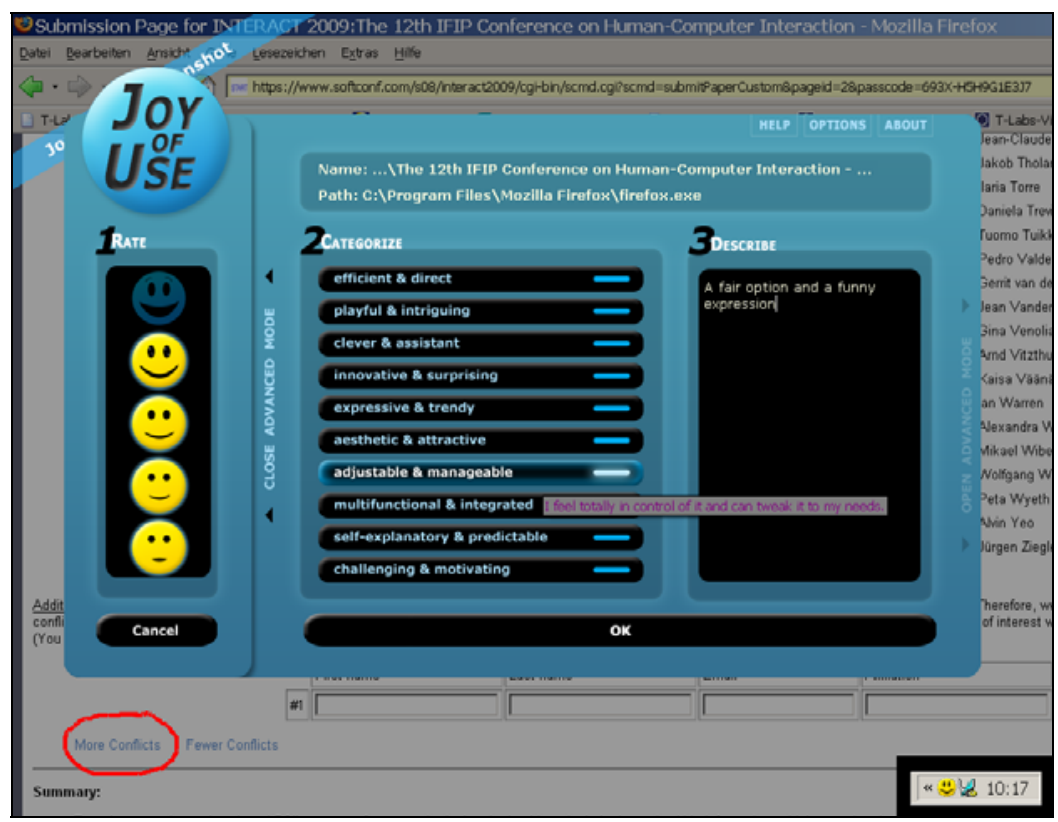

Fig. 1. the Joy-of-Use-Button interface in advanced mode. In the simple mode, only the smiley scale is present (1). In the advanced mode, common aspects of Joy-of-Use epxeriences can be selected (2), whereby each item is briefly described in a tooltip-statement which is visible for the item 'adjustable \& manageable' here. Additional remarks can be entered in the free text field (3). In the background a screenshot of the currently open application, where the user marked the 'More conflicts' link in the left lower corner to specify what specifically caused the Joy-ofUse moment. In the right lower corner the icon as it appears in the system tray.

interface pops up. There are two versions of the interface: In the simple mode, she just has to give a rating on the five step smiley-scale, the dialogue window disappears and she can continue working. Her rating as well as a the path of the currently active application is saved as ASCII data, together with a screenshot of the current active window where the user can also mark areas of interest while the JoU-Button is active. In the advanced mode, she can additionally select up to ten properties that had been previously identified as characteristic of JoU-moments or make further remarks in a free text field. Figure 1 shows the functionalities of the advanced mode.

\section{Summary and Conclusion}

This project explored Joy-of-Use in humane-machine interactions and how to adequately record it in an applied environment. The collection of self-experienced Joyof-Use moments as well as their categorization are surely neither exhaustive nor final and need to be validated in further studies. However, the intention was to get an idea about general characteristics of these kinds of events. One central finding was that many moments of enjoyable interaction are not that intense and are of short duration, or at least, their conscious reflection 'I like this' is only present for a brief moment. To 
capture these moments, a measurement device should be available on the spot and operable without requiring many resources that have to be deduced from the task one is enjoying at the moment. For a similar reason we also refrained from implementing a paced or automatic pop-up prompt for a rating - it would possibly interrupt the flow and as such alter the phenomenon it is trying to measure.

At the present stage, the main purpose of this application is to allow other researchers and practitioners to compare our observations with their own experiences. If it turns out that the present verbal labels in the advanced mode are not satisfying, they can be easily changed in the source code that is also available on the homepage. All recorded data are stored locally and only accessible to the current user. Those who are willing to make their recordings available for further analysis can send them to joyofuse@qu.tlabs.tu-berlin.de . All data will be used for scientific purposes only and processed anonymously.

Aknowledgements. We would like to thank the participants of both student projects for their collaboration.

\section{References}

1. Hassenzahl, M., Tractinsky, N.: User experience - a research agenda. Behaviour \& Information Technology 25, 91-97 (2006)

2. Norman, D.A.: Emotional design: why we love (or hate) everyday things. Basic Books, New York City (2004)

3. Hassenzahl, M.: The Thing and I: Understanding the Relationship Between User and Product. In: Blythe, M.A., Overbeeke, K., Monk, A.F., Wright, P.C. (eds.) Funology. From Usability to Enjoyment, pp. 31-42. Kluwer Academic Publishers, Dordrecht (2004)

4. Nielssen, J.: User empowerment and the fun factor. In: Blythe, M.A., Overbeeke, K., Monk, A.F., Wright, P.C. (eds.) Funology. From Usability to Enjoyment, pp. 103-105. Kluwer Academic Publishers, Dordrecht (2004)

5. Lemonick, M.D.: The biology of joy. Time. 165, A12-4, A17 (2005)

6. Kirakowski, J., Corbett, M.: SUMI: The Software Usability Measurement Inventory. British Journal of Educational Technology 24, 210-212 (1993)

7. Hassenzahl, M., Burmester, M., Koller, F.: AttrakDiff: Ein Fragebogen zur Messung wahrgenommener hedonischer und pragmatischer Qualität. In: Szwillus, G., Ziegler, J. (eds.) Mensch \& Computer 2003. Interaktion in Bewegung, pp. 187-196. Teubner, Stuttgart (2003)

8. Bradley, M.M., Lang, P.J.: Measuring emotion: the Self-Assessment Manikin and the Semantic Differential. Journal of Behavior Therapy and Experimental Psychiatry 25, 49-59 (1994) 